\title{
Medicinal Plants Used by Various Tribes of Bangladesh for Treatment of Malaria
}

\author{
Mohammed Rahmatullah, Shahadat Hossan, Afsana Khatun, Syeda Seraj, and Rownak Jahan \\ Department of Biotechnology \& Genetic Engineering, University of Development Alternative, Dhanmondi, Dhaka 1205, Bangladesh \\ Correspondence should be addressed to Mohammed Rahmatullah, rahamatm@hotmail.com
}

Received 7 December 2011; Revised 12 January 2012; Accepted 12 January 2012

Academic Editor: Giampietro Corradin

Copyright (C) 2012 Mohammed Rahmatullah et al. This is an open access article distributed under the Creative Commons Attribution License, which permits unrestricted use, distribution, and reproduction in any medium, provided the original work is properly cited.

\begin{abstract}
It has been estimated that 300-500 million malaria infections occur on an annual basis and causes fatality to millions of human beings. Most of the drugs used for treatment of malaria have developed drug-resistant parasites or have serious side effects. Plant kingdom has throughout the centuries proved to be efficient source of efficacious malarial drugs like quinine and artemisinin. Since these drugs have already developed or in the process of developing drug resistance, it is important to continuously search the plant kingdom for more effective antimalarial drugs. In this aspect, the medicinal practices of indigenous communities can play a major role in identification of antimalarial plants. Bangladesh has a number of indigenous communities or tribes, who because of their living within or in close proximity to mosquito-infested forest regions, have high incidences of malaria. Over the centuries, the tribal medicinal practitioners have treated malaria with various plant-based formulations. The objective of the present study was to conduct an ethnomedicinal survey among various tribes of Bangladesh to identify the plants that they use for treatment of the disease. Surveys were conducted among seven tribes, namely, Bawm, Chak, Chakma, Garo, Marma, Murong, and Tripura, who inhabit the southeastern or northcentral forested regions of Bangladesh. Interviews conducted with the various tribal medicinal practitioners indicated that a total of eleven plants distributed into 10 families were used for treatment of malaria and accompanying symptoms like fever, anemia, ache, vomiting, and chills. Leaves constituted $35.7 \%$ of total uses followed by roots at $21.4 \%$. Other plant parts used for treatment included barks, seeds, fruits, and flowers. A review of the published scientific literature showed that a number of plants used by the tribal medicinal practitioners have been scientifically validated in their uses. Taken together, the plants merit further scientific research towards possible discovery of novel compounds that can be used to successfully treat malaria with less undesirable sideeffects.
\end{abstract}

\section{Introduction}

According to World Health Organization (WHO), malaria has afflicted human beings since antiquity [1]. The disease is caused by a protozoan of the genus Plasmodium and is transmitted through bites by female mosquitoes of the genus Anopheles. Five subspecies of Plasmodium, including P. falciparum, P. malariae, P. ovale, $P$. knowlesi, and $P$. vivax can cause malaria, and $90 \%$ of known human deaths are caused by $P$. falciparum. Plasmodium enters the blood stream through mosquito bites, where they infect and destroy red blood cells leading to the various symptoms of malaria, including chills, muscle ache, fever, nausea, and vomiting, and even coma, anemia, and severe respiratory problems. It has been estimated that 300-500 million malaria infections occur worldwide on an annual basis [2].

The antimalarial drug, quinine, whose use has been documented almost 400 years ago [3], was isolated from the bark of the Cinchona tree, which in addition also contains three other antimalarial compounds, namely, quinidine, cinchonine, and cinchonidine [4]. A common antimalarial drug in use today is chloroquine, a synthetic derivative of quinine. Use of quinine is challenged by its poor tolerability and poor compliance with complex dosing regimens; in addition, there have been concerns about potential interactions between quinine and antiretroviral and antitubercular drugs in human immunodeficiency virus and tuberculosisaffected patients [3]. Pruritus is a common adverse effect of 
chloroquine administration in African patients [5]. Moreover, the drugs are rapidly losing their value as antimalarial drugs because of emergence of drug-resistant strains of Plasmodium. The latest antimalarial drug is artemisinin, which is derived from the plant Artemisia annua L. (Asteraceae), and has been used in Chinese traditional medicine for more than 1,000 years for treatment of malaria. Artemisininderived antimalarial drugs like artesunate and artelinic acid reportedly caused embryo death and malformations in pregnant rats by killing embryonic erythroblasts [6]. Some findings indicate that $P$. falciparum strains may be developing resistant varieties to artemisinin in China. The $\mathrm{IC}_{50}$ of artemisinin in African strains of P. falciparum is reportedly 6-25 nM, while Chinese strains have $\mathrm{IC}_{50}$ value of about 630 $\mathrm{nM}$ [7].

Current treatment against malaria infections include combination therapies utilizing artemisinin or artemisininderivatives and other antimalarial drugs like amodiaquine, lumefantrine, mefloquine, primaquine, sulfadoxine, pyrimethamine, or chloroquine. As a precaution against further development of artemisinin-resistant Plasmodium strains, current therapeutic strategy involves use of artemisinin only with other antimalarial drugs [8]. However, it can be said with some certainty, that the present combination therapies, will in due course of time and possibly within a few years, develop drug-resistant strains of Plasmodium. The search for antimalarial drugs thus becomes a continuous process of developing newer drugs against already emergent or possibly emerging resistant strains of Plasmodium. Since plant kingdom has proven an effective source of antimalarial drugs in the past, and since about 1,200 plant species are used in traditional medicines of the world for treatment of malaria [2], these plant species may prove to be a valuable reservoir for discovery of a continuous series of newer effective drugs against malaria. One has, therefore, to look into the medicinal practices of indigenous communities for information on antimalarial plants, since indigenous communities, present in virtually all countries of the world, have centuries-old experience about the use of such plants and have extensive knowledge obtained through generations of usage on medicinal properties of various plant species.

Bangladesh has a number of indigenous communities or tribes. Some of the well-known tribes include the Chak, Chakma, Marma, Murong, Tripura, and Bawm tribes, who inhabit the forested regions of the Chittagong Hill Tracts in southeastern Bangladesh. The Garos are a major tribe inhabiting the forested regions of the northcentral regions of the country. Malaria is prevalent in Bangladesh with the highest prevalence noted in the southeast, north, and northeast parts with around $15 \%$ of the population reported as suffering from malaria in these areas, especially the southeast, and particularly among the tribal people inhabiting these regions $[9,10]$. Tribal people, till even now, frequent their own tribal medicinal practitioners (TMPs) for treatment of malaria. It has been reported that $60-70 \%$ of the Chakma, Marma, and Tripura tribal people frequent their own TMPs for malaria treatment [11]. The objective of the present study was to conduct a survey among the TMPs of the above-mentioned tribes to gather information on the medicinal plants used by them for treatment of malaria.

\section{Materials and Methods}

The present survey was conducted between October 2009 and May 2011 among TMPs of Bawm, Chak, Chakma, Marma, Murong, and Tripura tribes inhabiting Khagrachari and Bandarban districts of Chittagong Hill Tracts region of Bangladesh, and TMPs of the Garo tribe inhabiting adjoining villages in Tangail and Mymensingh districts of Bangladesh. The study protocol was approved by the Research Ethics Committee of the University of Development Alternative. The number of TMPs living among the Bawm, Chak, Chakma, Marma, Murong, Tripura, and Garo communities surveyed were, respectively, $4,4,7,6,6,5$, and 7 . In total, the number of TMPs consulted from the seven tribes was 28 (four per tribe- the authors decided to take the same number of TMPs from each tribe, and since the Bawm and Chak tribes had the least number of TMPs at 4, this number was selected to be taken as the number of TMPs to be interviewed from the other tribes also). Among tribes, which had more than 4 serving TMPs, 4 were chosen on the basis of the recommendation of the tribal Headman as to being more proficient in their practices. At the request of the TMPs from any individual tribe, interviews were conducted of the four TMPs per tribe as a group. Informed consent was initially obtained from the TMPs and the tribal Headman (chieftain) to gather the necessary information. Both TMP and the Headman was apprised in details as to the purpose of our visits, and consent obtained to disseminate the names and formulations (if any) of antimalarial plants both nationally and internationally. Interviews were usually conducted through an interpreter, who can speak both the tribal language as well as Bangla (the language spoken by the interviewers). It may be mentioned that in recent years most tribes have acquired sufficient proficiency in speaking and understanding Bangla, which is the language of the mainstream population (around 98\%) of Bangladesh.

Interviews were open-ended and conducted with the help of a semistructured questionnaire. TMPs were specifically asked as to whether they know and treat malaria, the basis for their diagnosis, and their mode of treatment when the disease has been diagnosed as malaria. The general patterns of diagnosing malaria were more or less the same among the TMPs of the various types. The symptoms of malaria, according to the TMPs, were fever (particularly fever arising daily at certain parts of the day or night followed by subsiding and recurrence), chills, pain (throughout the body but mostly affecting the muscles or back), sweats, fatigue, nausea, vomiting, and a general wasting away of the body with time. TMPs were allowed to speak freely on malarial treatment with medicinal plants with only occasional interference and questions from the interviewers. TMP-guided field walks were arranged where the TMPs took the interviewers on field walks through areas from where the TMPs collected the medicinal plants, pointed out the plants, and described their uses. Plant materials were collected 
and dried on the spot, photographed and brought back to Dhaka for identification by Mr. Manjur-Ul-Kadir Mia, exCurator and Principal Scientific Officer of the Bangladesh National Herbarium. Voucher specimens were deposited at the Medicinal Plant Collection Wing of the University of Development Alternative, where the initial identification was reconfirmed by a botanist at the Medicinal Plant Collection Wing of the University.

\section{Results}

It was observed that the TMPs of the 7 tribes surveyed used a total of 11 plants distributed into 10 families for treatment of malaria. The Fabaceae family was the only family contributing 2 plants; the rest of the plant families contributed one plant each. The various plant parts used included leaves, roots, barks, seeds, fruits, and flowers. Leaves constituted the major plant part used, forming $35.7 \%$ of total uses. Roots constituted $21.4 \%$ of total uses. The other plant parts mentioned constituted, respectively, 14.3, 14.3, 7.1, and $7.1 \%$ of total uses.

According to the TMPs of the various tribes surveyed, their medicinal knowledge was derived from earlier generation practitioners, with whom every TMP had to serve a period of apprenticeship and training before they could practice independently. As such, tribal medicinal knowledge has come out of practice through the centuries and apparently every tribe had, so to say, their own lists of plants for treatment of any particular ailment. It was therefore no surprise that all four TMPs of any individual tribe surveyed pointed out the same plants for treatment of malaria. Moreover, as mentioned earlier, all 4 TMPs of any particular tribe surveyed were interviewed as a group at their request, and so the plants mentioned by the TMPs of a particular tribe were the result of a general consensus among the TMPs of the tribe and did not reflect any individual opinion. It was the conclusion of the interviewers that malaria had existed for centuries among the tribal people surveyed, and various tribes have developed their own medicinal plant formulations for treatment of this disease, possibly through trial and error methods over centuries-long practices.

Any sort of complex formulations was avoided by the TMPs for treatment of malaria. Fruits and seeds were consumed directly or with water. In most cases, juice obtained from squeezed plant part was advised to be taken, or pills made from paste of plant part taken orally. In two instances, it was noted that plant part was advised to be taken with either black pepper or rice. A paste of roots of Rauwolfia serpentina and black peppers was advised to be taken for malaria by TMPs of the Garo tribe. Juice obtained from roots of Amaranthus spinosus was advised to be taken with powdered rice and water by TMPs of the Murong tribe. Formulations were usually administered orally with two exceptions. The TMPs of the Murong tribe advised leaves of the plant Mussaenda corymbosa to be boiled in water and the malaria patient sponged and bathed in that water. The TMPs of the Bawm tribe advised leaf infusion of the same plant to be used for shower by the malaria patient; alternately, the patient's body was rubbed with the infusion for a while. Notably, this plant was exceptional from two points; not only this plant was the only plant whose plant part (leaf) was administered topically but also among the eleven plants used for treatment by the seven tribes, this plant was the only common plant to be used by two tribes-Bawm and Murong. What is notable in this regard is that while the Bawm, Chak, Chakma, Marma, Murong, and the Tripura tribes inhabit adjoining forest regions containing similar flora of the same general area (Chittagong Hill Tracts), the TMPs of these tribes use different plants for treatment of malaria.

Although the Chakma tribe is the major tribe of the Chittagong Hill Tracts region, their TMPs used only 2 plants for treatment of malaria. In contrast, the TMPs of the Murong and the Tripura tribes used three plants each for treatment. While the medicinal plants were advised to be used by the TMPs of six tribes to be used for a certain number of days (usually 7) or till cure, the Chak TMPs provided a total exception to this rule. Their method for treatment of malaria was to take 3 powdered seeds of Caesalpinia nuga with water only once. The Chak TMPs claimed that a single administration of the seeds of the above plant was sufficient to cure malaria irrespective of its severity or duration (see Table 1).

\section{Discussion}

It is always of interest to determine whether the plants used by traditional medicinal practitioners for treatment of various ailments can be validated through existing scientific studies. Towards that, available scientific literature was screened for reports that may validate the use of the antimalarial plants of the seven tribes surveyed. Procyanidins have been isolated from fruits of Adansonia digitata [12]; a number of procyanidins have been reported to possess antiplasmodial activity [13-16]. Scoparia dulcis, similar to its antimalarial usage by the Murong TMPs in Bangladesh, is also used by native Amazonian groups from the Nanay River (Peru) for treatment of malaria [17]. Scopadulcic acid A has been isolated from the plant, which has been found to inhibit $P$. falciparum strains D6 and W2 in vitro with $\mathrm{IC}_{50}$ values of 27 and $19 \mu \mathrm{M}$, respectively. The compound has further been shown to be active against the multidrugresistant strain TM91C235 with an $\mathrm{IC}_{50}$ value of $23 \mu \mathrm{M}$ [18].

Extract of Streblus asper reportedly exhibited antimalarial properties against murine malaria [19]. Lupeol and oleanolic acids have been reported from leaves and aerial parts of the plant $[20,21]$. Lupeol and lupeol-derivatives have been reported to possess antiplasmodial activity according to a number of reports [22-24]. Oleanolic acid has also been reported to possess antiplasmodial activity. Epioleanolic acid has been isolated through bioactivity-guided fractionation of whole plant of Viola verecunda with high antiplasmodial activity against chloroquine-resistant FcB1 strain of $P$. falciparum with an $\mathrm{IC}_{50}$ value of $0.18 \mu \mathrm{g} / \mathrm{mL}$ [25].

Although any scientific report is absent on the antimalarial properties of Caesalpinia nuga, other species from 
TABLE 1: Medicinal plants used by various tribes of Bangladesh for treatment of malaria and accompanying symptoms.

\begin{tabular}{|c|c|c|c|c|c|}
\hline $\begin{array}{l}\text { Serial } \\
\text { number }\end{array}$ & Botanical name & Family & $\begin{array}{l}\text { Local name } \\
\text { (tribe) }\end{array}$ & Parts used & Dosage \\
\hline 1 & $\begin{array}{c}\text { Caesalpinia nuga (L.) W. T. } \\
\text { Aiton }\end{array}$ & Fabaceae & $\begin{array}{l}\text { Krung-khai } \\
\text { (Chak) }\end{array}$ & Seed & $\begin{array}{l}\text { Three seeds are powdered mixed } \\
\text { with water and taken only once } \\
\text { for cure. }\end{array}$ \\
\hline 2 & Adansonia digitata $L$. & Bombacaceae & $\begin{array}{l}\text { Kattio-daghor } \\
\text { (Chakma) }\end{array}$ & $\begin{array}{l}\text { Leaf, root, } \\
\text { flower }\end{array}$ & $\begin{array}{l}\text { A combination of leaves, roots, } \\
\text { and flowers is taken till cure. }\end{array}$ \\
\hline 3 & Jatropha gossypifolia L. & Euphorbiaceae & $\begin{array}{l}\text { Titto-long } \\
\text { (Chakma) }\end{array}$ & Seed & $\begin{array}{c}\text { Seeds are taken with water till } \\
\text { cure. }\end{array}$ \\
\hline 4 & Rauwolfia serpentina Benth. & Apocynaceae & $\begin{array}{l}\text { Sharpagandha } \\
\text { (Garo) }\end{array}$ & Root & $\begin{array}{c}\text { A paste of root and black pepper } \\
\text { is administered }(\text { dose equal to } \\
4-5 \text { ratis, } 1 \text { rati }=1 \text { tola }=11.66 \mathrm{~g}) \\
\text { till cure. }\end{array}$ \\
\hline 5 & Hodgsonia macrocarpa Cogn. & Cucurbitaceae & $\begin{array}{l}\text { Keha-pang } \\
\text { (Marma) }\end{array}$ & Fruit & The fruits are taken till cure. \\
\hline 6 & Erythrina variegata $\mathrm{L}$. & Fabaceae & $\begin{array}{l}\text { Mada-kamia- } \\
\text { mafang } \\
\text { (Tripura) }\end{array}$ & Bark & $\begin{array}{l}\text { Bark paste is made into pills and } \\
\text { the pills taken till cure. }\end{array}$ \\
\hline 7 & Streblus asper Lour. & Moraceae & Sarwa (Tripura) & Bark & $\begin{array}{l}\text { Juice obtained from squeezed } \\
\text { bark is taken till cure. }\end{array}$ \\
\hline 8 & Clerodendrum viscosum Vent. & Verbenaceae & $\begin{array}{l}\text { Kung-sroi-ma } \\
\text { (Tripura) }\end{array}$ & Leaf & $\begin{array}{l}\text { One teaspoonful leaf juice is } \\
\text { taken } 3 \text { times daily for a week. }\end{array}$ \\
\hline 9 & Amaranthus spinosus $\mathrm{L}$. & Amaranthaceae & $\begin{array}{l}\text { Kang-chuo } \\
\text { (Murong) }\end{array}$ & Root & $\begin{array}{c}\text { Juice obtained from squeezed } \\
\text { roots is mixed with powdered } \\
\text { rice and taken with water till } \\
\text { cure. }\end{array}$ \\
\hline \multirow[t]{2}{*}{10} & \multirow{2}{*}{$\begin{array}{c}\text { Mussaenda corymbosa A.L. de } \\
\text { Jussieu }\end{array}$} & \multirow[t]{2}{*}{ Rubiaceae } & $\begin{array}{l}\text { Mok-ae } \\
\text { (Murong) }\end{array}$ & Leaf & $\begin{array}{l}\text { Leaves are boiled thoroughly in } \\
\text { water. The patient is both } \\
\text { sponged and bathed in the water } \\
\text { till cure. }\end{array}$ \\
\hline & & & $\begin{array}{l}\text { Thalepat harkep } \\
\text { (Bawm) }\end{array}$ & Leaf & $\begin{array}{c}\text { Leaf infusion is taken for shower } \\
\text { or whole body rubbed with the } \\
\text { infusion for a while every day till } \\
\text { cure. }\end{array}$ \\
\hline 11 & Scoparia dulcis L. & Scrophulariaceae & $\begin{array}{l}\text { Tapra-amkanlu } \\
\quad \text { (Murong) }\end{array}$ & Leaf & $\begin{array}{l}\text { Juice squeezed from leaves is } \\
\text { taken two teaspoon full daily in } \\
\text { the morning and evening for } 7 \\
\text { days or till cure. }\end{array}$ \\
\hline
\end{tabular}

the same genus are reported to contain phytochemical constituents with strong antiplasmodial activities. Cassane and norcassane-type diterpenes are in general present in the Caesalpinia genus. Three cassane furano diterpenoids, all with good activity against multidrug-resistant K1 strain of $P$. falciparum, have been reported from seed kernels of $C$. bonduc [26]. Methyl chloride extract of seed kernels of C. crista L. reportedly demonstrated promising antimalarial activity against $P$. berghei-infected mice in vivo. Chemical analysis of the extract resulted in the isolation of furanocassanetype diterpenes. The isolated diterpenes showed significant inhibitory effects on $P$. falciparum FCR-3/A2 growth in vitro, with $\mathrm{IC}_{50}$ values ranging from $90 \mathrm{nM}$ to $6.5 \mu \mathrm{M}$. Among the isolated diterpenes, norcaesalpinin $\mathrm{E}$ had the lowest $\mathrm{IC}_{50}$ concentration at $90 \mathrm{nM}$ [27]. Norcaesalpinin E has also been reported to possess the most potent activity against $P$. falciparum FCR-3/A2 clone in vitro among 44 cassane- and norcassane-type diterpenes isolated from C. crista of Myanmar and Indonesia [28].

The available scientific literature strongly suggests that at least some of the plants used by the TMPs of various tribes of Bangladesh may have strong scientific basis for their use in the treatment of malaria. It may be pointed out in this regard that since malaria has affected human beings from antiquity, medical practitioners of various tribes and later nations have used various remedies to treat the disease. Medicinal plants have formed possibly the strongest component of such antimalarial remedies. Also the history of long usage of such medicinal plants for treatment of malaria by TMPs of Bangladesh indicates that these plants have proved to a greater or lesser extent successful in the treatment of malaria and/or associated symptoms. Taken together, the eleven medicinal plants used by the TMPs of Bangladesh merits further research towards discovery of 
novel and efficacious antimalarial drugs. C. nuga can be taken as a prime example to work upon. While this plant is yet to be studied scientifically, other species from the same genus reportedly contains strong antimalarial constituents. It is also noteworthy that the TMPs use a single dose of the seeds of this plant to treat malaria, suggesting that the seeds may contain some very effective antimalarial or antiplasmodial compounds. Antiplasmodial and cytotoxicity studies on the various antimalarial plants and plant parts need to be carried out and will be done in the next phase of this study.

\section{References}

[1] L. J. Bruce-Chwatt, Chemotherapy of Malaria, World Health Organization, Geneva, Switzerland, 2nd edition, 1986.

[2] G. Bodeker, "Introduction," in Traditional Medicinal Plants and Malaria, M. Willcox, G. Bodeker, and P. Rasoanaivo, Eds., pp. 1-3, CRC Press, New York, NY, USA, 2004.

[3] J. A. O. Achan, A. Talisuna, A. Erhart et al., "Quinine, an old anti-malarial drug in a modern world: role in the treatment of malaria," Malaria Journal, vol. 10, pp. 144-155, 2011.

[4] A. S. Fabiano-Tixier, A. Elmori, A. Blanckaert, E. Seguin, E. Petitcolas, and F. Chemat, "rapid and green analytical method for the determination of quinoline alkaloids from Cinchona succirubra based on microwave-integrated extraction and leaching (MIEL) prior to high performance liquid chromatography," International Journal of Molecular Sciences, vol. 12, no. 11, pp. 7846-7860, 2011.

[5] W. R. Taylor and N. J. White, "Antimalarial drug toxicity: a review," Drug Safety, vol. 27, no. 1, pp. 25-61, 2004.

[6] R. L. Clark, K. C. Brannen, J. E. Sanders, and A. M. Hoberman, "Artesunate and artelinic acid: association of embryotoxicity, reticulocytopenia, and delayed stimulation of hematopoiesis in pregnant rats," Birth Defects Research B, vol. 92, no. 1, pp. 52-68, 2011.

[7] C. Wongsrichanalai, T. D. Nguyen, N. T. Trieu et al., "In vitro susceptibility of Plasmodium falciparum isolates in Vietnam to artemisinin derivatives and other antimalarials," Acta Tropica, vol. 63, no. 2-3, pp. 151-158, 1997.

[8] S. Y. Whegang, R. Tahar, V. N. Foumane et al., "Efficacy of non-artemisinin- and artemisinin-based combinationtherapies for uncomplicated falciparum malaria in Cameroon," Malaria Journal, vol. 9, no. 1, pp. 56-65, 2010.

[9] W. A. Khan, D. A. Sack, S. Ahmed et al., "Mapping hypoendemic, seasonal malaria in rural Bandarban, Bangladesh: a prospective surveillance," Malaria Journal, vol. 10, article 124, 2011.

[10] U. Haque, T. Sunahara, M. Hashizume et al., "malaria prevalence, risk factors and spatial distribution in a hilly forest area of Bangladesh," PLoS One, vol. 6, no. 4, Article ID e18908, 9 pages, 2011.

[11] S. M. Ahmed, "Differing health and health-seeking behaviour: ethnic minorities of the Chittagong Hill Tracts, Bangladesh," Asia-Pacific Journal of Public Health, vol. 13, no. 2, pp. 100$108,2001$.

[12] A. A. Shahat, "Procyanidins from Adansonia digitata", Pharmaceutical Biology, vol. 44, no. 6, pp. 445-450, 2006.

[13] A. R. Sannella, L. Messori, A. Casini et al., "Antimalarial properties of green tea," Biochemical and Biophysical Research Communications, vol. 353, no. 1, pp. 177-181, 2007.
[14] T. Banerjee, S. K. Sharma, N. Surolia, and A. Surolia, "Epigallocatechin gallate is a slow-tight binding inhibitor of enoylACP reductase from Plasmodium falciparum," Biochemical and Biophysical Research Communications, vol. 377, no. 4, pp. 1238-1242, 2008.

[15] V. Ramanandraibe, P. Grellier, M. T. Martin et al., "Antiplasmodial phenolic compounds from Piptadenia pervillei," Planta Medica, vol. 74, no. 4, pp. 417-421, 2008.

[16] Y. J. Park, I. M. Chung, and H. I. Moon, "Antiplasmodial procyanidins derivatives from Chinese Hawthorn," Immunopharmacology and Immunotoxicology, vol. 32, no. 4, pp. 607-610, 2010.

[17] L. Ruiz, L. Ruiz, M. Maco, M. Cobos, A. L. GutierrezChoquevilca, and V. Roumy, "Plants used by native Amazonian groups from the Nanay River (Peru) for the treatment of malaria," Journal of Ethnopharmacology, vol. 133, no. 2, pp. 917-921, 2011.

[18] M. A. Riel, D. E. Kyle, and W. K. Milhous, "Efficacy of scopadulcic acid A against Plasmodium falciparum in vitro," Journal of Natural Products, vol. 65, no. 4, pp. 614-615, 2002.

[19] M. K. Das and M. K. Beuria, "Anti-malarial property of an extract of the plant Streblus asper in murine malaria," Transactions of the Royal Society of Tropical Medicine and Hygiene, vol. 85, no. 1, pp. 40-41, 1991.

[20] K. Mukherjee and L. N. Roy, "Chemical examination of Streblus asper leaves," International Journal of Crude Drug Research, vol. 21, no. 4, pp. 189-190, 1983.

[21] A. S. Chawla, V. K. Kapoor, R. Mukhopadhyay, and M. Singh, "Constituents of Streblus asper," Fitoterapia, vol. 61, no. 2, p. $186,1990$.

[22] E. O. Ajaiyeoba, J. S. Ashidi, L. C. Okpako, P. J. Houghton, and C. W. Wright, "Antiplasmodial compounds from Cassia siamea stem bark extract," Phytotherapy Research, vol. 22, no. 2, pp. 254-255, 2008.

[23] J. Fotie, D. S. Bohle, M. L. Leimanis, E. Georges, G. Rukunga, and A. E. Nkengfack, "Lupeol long-chain fatty acid esters with antimalarial activity from Holarrhena floribunda," Journal of Natural Products, vol. 69, no. 1, pp. 62-67, 2006.

[24] S. Kumar, N. Misra, K. Raj, K. Srivastava, and S. K. Puri, "Novel class of hybrid natural products derived from lupeol as antimalarial agents," Natural Product Research, vol. 22, no. 4, pp. 305-319, 2008.

[25] H. I. Moon, J. C. Jung, and J. Lee, "Antiplasmodial activity of triterpenoid isolated from whole plants of Viola genus from South Korea," Parasitology Research, vol. 100, no. 3, pp. 641644, 2007.

[26] K. Pudhom, D. Sommit, N. Suwankitti, and A. Petsom, "Cassane furanoditerpenoids from the seed kernels of Caesalpinia bonduc from Thailand," Journal of Natural Products, vol. 70, no. 9, pp. 1542-1544, 2007.

[27] T. Z. Linn, S. Awale, Y. Tezuka et al., "Cassane- and norcassanetype diterpenes from Caesalpinia crista of Indonesia and their antimalarial activity against the growth of Plasmodium falciparum," Journal of Natural Products, vol. 68, no. 5, pp. 706-710, 2005.

[28] S. K. Kalauni, S. Awale, Y. Tezuka et al., "Antimalarial activity of cassane- and norcassane-type diterpenes from Caesalpinia crista and their structure-activity relationship," Biological and Pharmaceutical Bulletin, vol. 29, no. 5, pp. 1050-1052, 2006. 


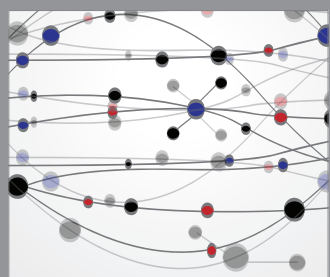

The Scientific World Journal
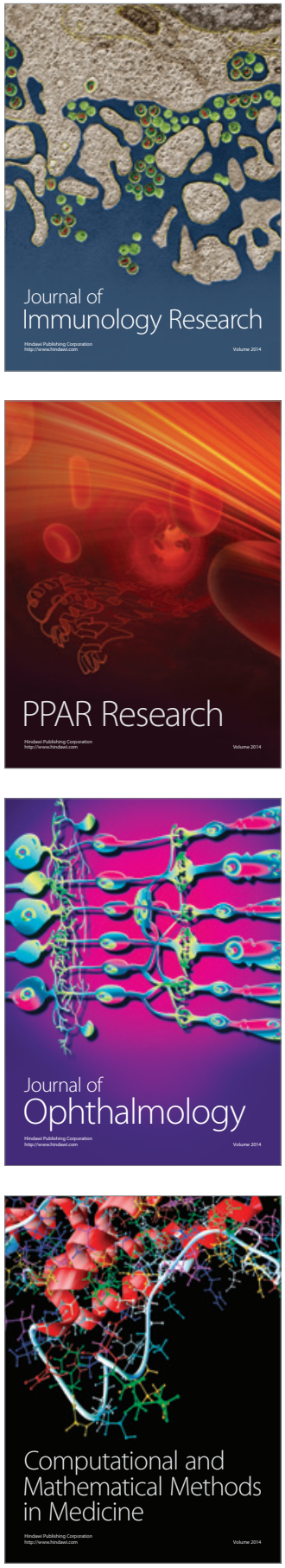

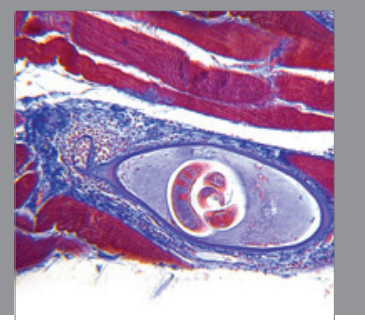

Gastroenterology

Research and Practice
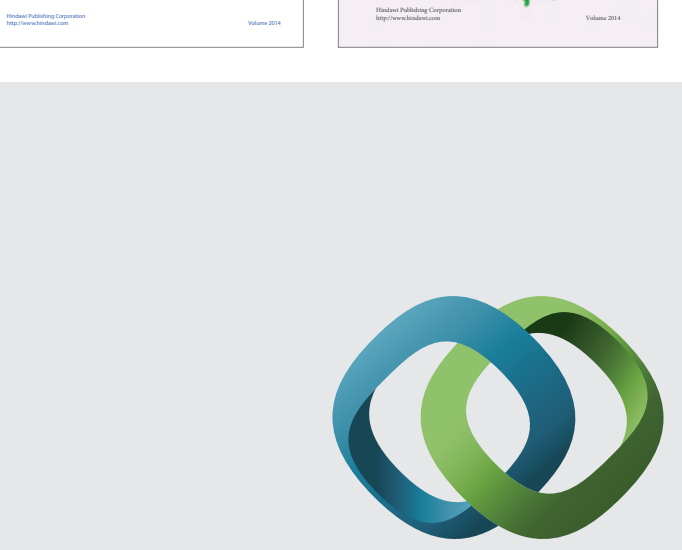

\section{Hindawi}

Submit your manuscripts at

http://www.hindawi.com
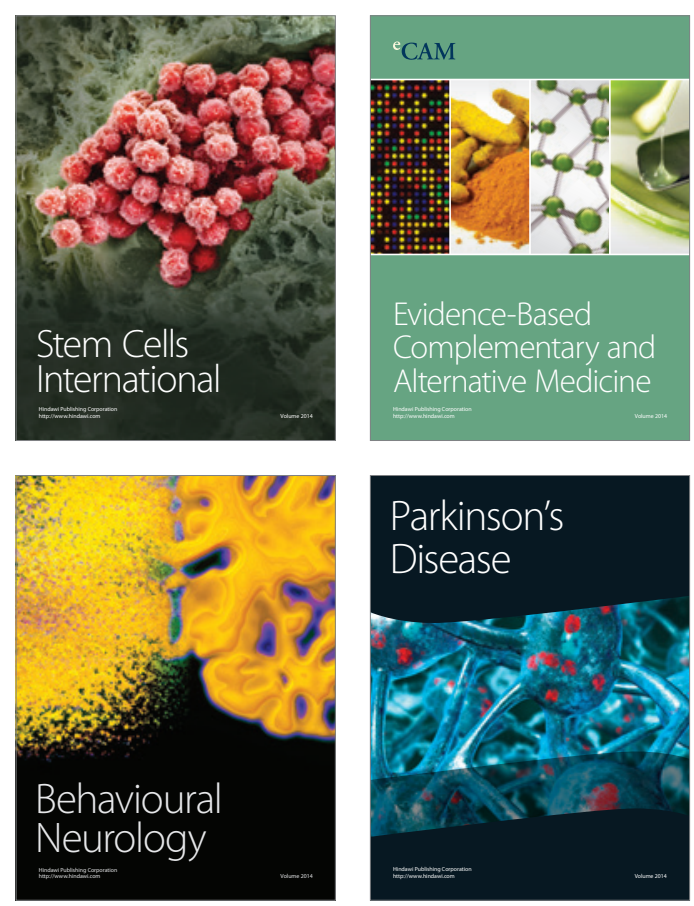

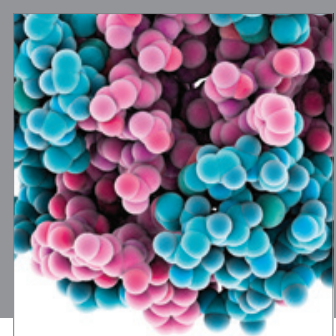

Journal of
Diabetes Research

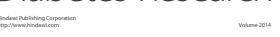

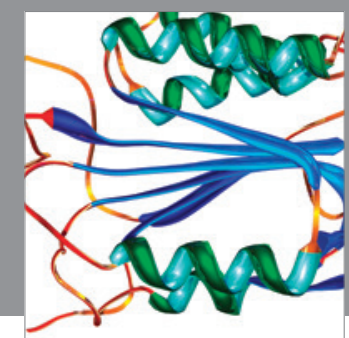

Disease Markers
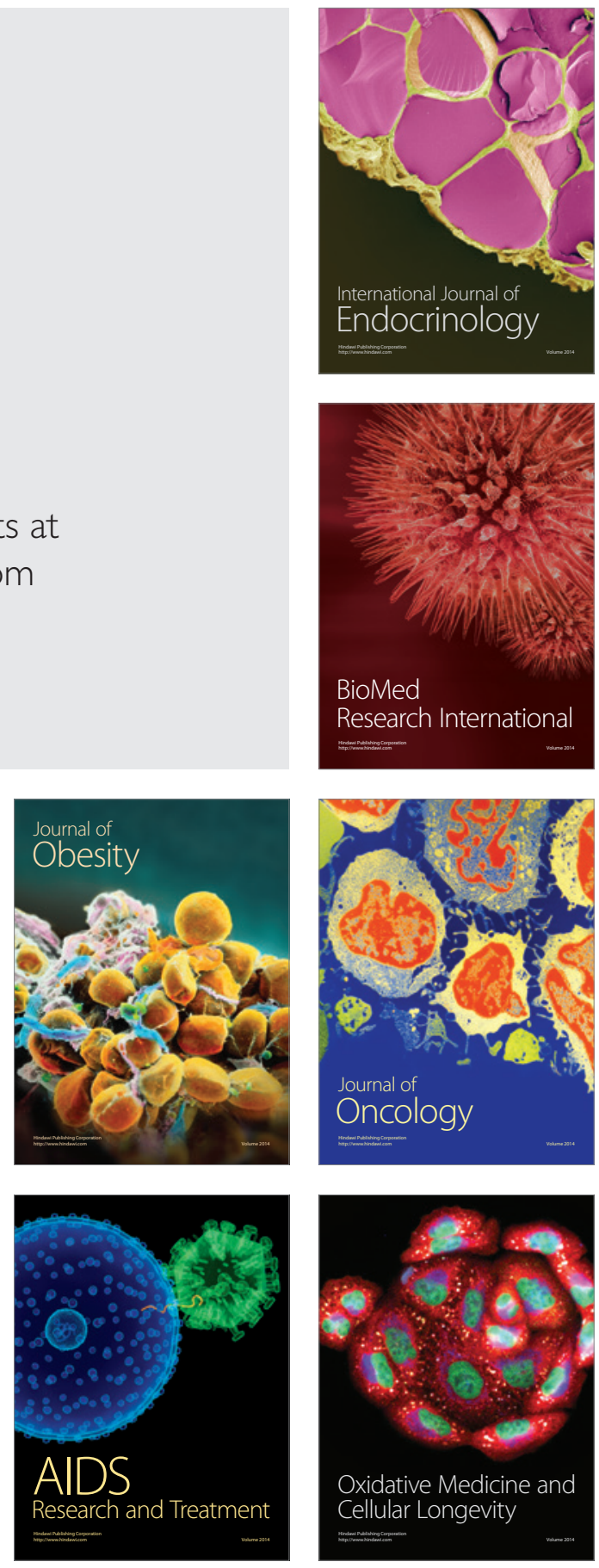